\title{
Gene expression profiles in primary pancreatic tumors and metastatic lesions of Ela-c-myc transgenic mice Archana Thakur ${ }^{\dagger}$, Aliccia Bollig ${ }^{\dagger}$, Jiusheng Wu and Dezhong J Liao*
}

\author{
Address: Department of Pathology, Karmanos Cancer Institute, Wayne State University School of Medicine, 110 E. Warren Ave., Detroit, Michigan \\ 48201, USA \\ Email: Archana Thakur - athakur@med.wayne.edu; Aliccia Bollig - abollig@med.wayne.edu; Jiusheng Wu - jwu@med.wayne.edu; \\ Dezhong J Liao* - djliao@hi.umn.edu \\ * Corresponding author †Equal contributors
}

Published: 24 January 2008

Molecular Cancer 2008, 7:II doi:10.1 I86/1476-4598-7-II
Received: 3 April 2007

Accepted: 24 January 2008

This article is available from: http://www.molecular-cancer.com/content/7/I/II

(C) 2008 Thakur et al; licensee BioMed Central Ltd.

This is an Open Access article distributed under the terms of the Creative Commons Attribution License (http://creativecommons.org/licenses/by/2.0), which permits unrestricted use, distribution, and reproduction in any medium, provided the original work is properly cited.

\begin{abstract}
Background: Pancreatic carcinoma usually is a fatal disease with no cure, mainly due to its invasion and metastasis prior to diagnosis. We analyzed the gene expression profiles of paired primary pancreatic tumors and metastatic lesions from Ela-c-myc transgenic mice in order to identify genes that may be involved in the pancreatic cancer progression. Differentially expressed selected genes were verified by semi-quantitative and quantitative RT-PCR. To further evaluate the relevance of some of the selected differentially expressed genes, we investigated their expression pattern in human pancreatic cancer cell lines with high and low metastatic potentials.
\end{abstract}

Results: Data indicate that genes involved in posttranscriptional regulation were a major functional category of upregulated genes in both primary pancreatic tumors (PT) and liver metastatic lesions (LM) compared to normal pancreas (NP). In particular, differential expression for splicing factors, RNA binding/pre-mRNA processing factors and spliceosome related genes were observed, indicating that RNA processing and editing related events may play critical roles in pancreatic tumor development and progression. High expression of insulin growth factor binding protein-I (lgfbpl) and Serine proteinase inhibitor AI (Serpinal), and low levels or absence of Wtl gene expression were exclusive to liver metastatic lesion samples.

Conclusion: We identified Igfbpl, Serpinal and WtI genes that are likely to be clinically useful biomarkers for prognostic or therapeutic purposes in metastatic pancreatic cancer, particularly in pancreatic cancer where c-Myc is overexpressed.

\section{Background}

Pancreatic cancer (PC) is the fourth leading cause of cancer death in the United States and has no cure, partly because the tumor is at advanced stage or has already metastasized at the time of diagnosis [1]. Like many other types of cancer, pancreatic cancer also shows high frequencies of overexpression and/or amplification of the c$m y c$ oncogene. In one study, $43.5 \%$ of primary tumors and $31.6 \%$ of metastases showed c-Myc overexpression, in association with $32.5 \%$ and $29.4 \%$ of gene amplification in the primary and metastatic lesions, respectively [2]. cMyc and cyclin D1 gene amplification was report 54\% and $28 \%$ in 31 pancreatic cancer cell lines, respectively, indicating a high frequency of concomitant amplification of both genes [3]. Moreover, simultaneous amplification of activated k-ras and c-myc has been found in both pri- 
mary tumor and lymph node metastasis, suggesting that cMyc may collaborate with other oncogenes to promote development and progression of pancreatic cancer [4]. More direct evidence for a critical role for c-Myc in pancreatic carcinogenesis comes from Ela-c-myc transgenic mice that develop PC between 2-7 months of age with 100\% incidence rate [5]. One-half of the pancreatic tumors that form in this mouse model are acinar cell adenocarcinomas, while the remaining half of the tumors are mixed ductal and acinar cell carcinomas embedded in dense stroma. We have recently described detailed morphological traits of the pancreatic tumors developed in this transgenic model [6,7] and, for the first time, observed spontaneous metastasis to the liver in this model. These transgenic mice are among the few animal models of liver metastasis of spontaneous PC. The whole carcinogenic process, from initiation to metastasis, is short (in only a few months time) and is initiated by only one gene.

The most devastating aspect of all types of cancer, particularly pancreatic cancer, is the emergence of metastases in organs distant from the primary tumor, and this remains the primary cause for the poor survival of patients with pancreatic cancer [8]. Therefore, a search for molecular markers that can predict poor prognosis and also serve as novel targets for the development of therapies against this most aggressive disease is warranted. Transgenic animals have been widely used to dissect the role of genes and molecular pathways in cancer [9]. Our transgenic model will help in understanding the molecular mechanisms by which metastases are generated, which is crucial for the prevention and treatment of metastatic disease. In this study we attempted to identify genes that may be responsible for the liver metastasis of pancreatic tumors in Ela$m y c$ transgenic mice.

\section{Results \\ cDNA Microarray Analysis and Global Gene Expression Profiles}

Microarray signal values were calculated from the multiple probes present on each chip for each condition and each condition was repeated at least three times. The relative intensity (fold change) of gene expression levels in the primary tumors (PT) compared to the normal pancreas (NP) is shown in Figure 1A (left panel) and fold change in gene expression in liver metastatic (LM) lesions compared to PT are presented in Figures 1A (right panel).

Cluster analysis was used to display the gene expression data of those, which showed 4-fold higher or 4-fold lower expression levels in PT and LM compared to NP samples. Before clustering, a filtering procedure eliminated genes with uniformly low expression or with low expression variation across the replicates. A large number of genes in PT and LM showed different expression from NP. However, the majority of genes did not show obvious distinction in their expression pattern between the PT and LM (Fig. 1B), except for a small number of genes (boxed area in Fig. 1B expanded in Fig. 1C), suggesting that the LM largely retain the properties of the primary tumors.

\section{Identification of potential tumor promoting genes in c- myc-induced pancreatic tumors}

Expressed genes were categorized on the basis of their functional properties, which showed at least 4-fold higher, or 4-fold lower expression levels in primary or metastatic pancreatic tumors compared to normal pancreas. Table 1 shows genes whose expression was upregulated in PT compared to NP (relative fold change) and also shows the relative fold change in LM compared to PT samples. Many upregulated genes such as Birc5, Ccna2, Ccnb1, Ccnb2, Mcm7, Nap1l1, Rad51, Smc4l1, Smc2l1, Rsk4, sfrs1, and sfrs2 (please see Table 1 for their full names) showed 5-20 fold higher expression levels, very few showed exceptionally high fold changes, for example calcium binding protein-S100g showed 109 fold higher expression level in PT than in NP. A large number of upregulated genes in PT belonged to the functional categories known for cell proliferation and cell cycle regulation, chromosomal organization and biogenesis, and RNA processing and modification. In Table 2, we show the genes whose expression was down regulated in PT compared to NP samples (relative fold change) as well as the fold change in LM compared to PT samples. Down regulation of some of the genes in Table 2 including Col4a4, Pcdh17, Muc2, Muc13 (please see Table 2 for their full names) has been shown to modulate cell adhesion and apoptosis.

Selected genes (highlighted in Table 1, 2 and 3) from various functional categories were further verified by RT-PCR for their expression patterns (Fig. 2A). This selection was based on results in the literature indicating a direct or indirect role for each candidate gene in RNA processing, cell signaling, cell proliferation or apoptosis and cell adhesion and motility activities resulting in tumor growth and tumor progression. Many of these genes listed in Table 1 and 2, such as Birc5, Brca1, Ccnb2, CXCR4, Mcm2, Mcm4, Mcm7, Nap1l1, Rad51, Sf3b, S100g [10-17]have been shown to be upregulated, while Cldn18, Muc2, Muc13, and b-myc [18-21] are shown to be down regulated in human pancreatic cancer as well as other types of cancer (please see Table 1 and 2 for their full names). However, strong expression of Muc13 in 50\% of samples as well as b-myc in pancreatic cancer cells was unexpected and needs further characterization.

We evidenced notable changes in the family members of insulin-like growth factor (Igf). While Igf1 expression was slightly decreased in tumors compared with normal pan- 



Figure I

Gene expression profiles. A) Histogram showing a similar (left) and differential (right) gene expression profiles of primary pancreatic tumors and liver metastatic lesions from Ela-c-Myc transgenic mice compared to normal pancreas from wild type littermates. B) Hierarchical clustering of differentially expressed genes. Clustering tree illustrate the expression pattern and similarity in primary pancreatic tumors (labeled as PT) and liver metastatic lesions (labeled as LM) compared to normal pancreas (labeled as NP) indicated by color bars. C) Shows only the differentially expressed gene profile with at least a four-fold change $(\leq 4$ or $\geq 4)$ indicated by color bars. (blue-down regulated and red up-regulated). 
Table I: Upregulated genes in primary pancreatic tumors. Relative fold change in primary pancreatic tumors compared to normal pancreas (PT/NP) and in liver metastatic lesions compared to primary pancreatic tumors (LM/PT).

\begin{tabular}{|c|c|c|c|c|c|}
\hline Entrez Gene & $\begin{array}{l}\text { Fold change } \\
\text { LM*/PT* }\end{array}$ & $\begin{array}{l}\text { Fold change } \\
\text { PT/NP* }\end{array}$ & Gene Symbol & Gene description & Ref.* \\
\hline \multicolumn{6}{|c|}{ Mitochondrial ribosomal subunits } \\
\hline 77721 & 1.0 & 4.2 & Mrps5 & Mitochondrial ribosomal protein S5 & \\
\hline 69527 & 1.0 & 4.5 & Mrps9 & Mitochondrial ribosomal protein S9 & \\
\hline 94063 & 1.0 & 4.1 & Mrpll6 & Mitochondrial ribosomal protein LI6 & \\
\hline 56284 & 0.9 & 5.0 & Mrpll9 & Mitochondrial ribosomal protein LI9 & \\
\hline 66407 & 0.8 & 4.1 & MrpsI5 & Mitochondrial ribosomal protein SI 5 & \\
\hline 64655 & 1.2 & 7.6 & Mrps22 & Mitochondrial ribosomal protein S22 & \\
\hline 64658 & 1.0 & 4.1 & Mrps25 & Mitochondrial ribosomal protein S25 & \\
\hline \multicolumn{6}{|c|}{ Nucleolar and nucleosome assembly proteins } \\
\hline 53605 & 0.9 & 13.5 & Nap III & Nucleosome assembly protein I-like I & 10,11 \\
\hline 110109 & 0.9 & 4.3 & Noll & Nucleolar protein I & \\
\hline 52530 & 1.0 & 10.0 & Nola2 & Nucleolar protein family A, member 2 & \\
\hline 100608 & 1.1 & 9.4 & Noc4l & Nucleolar complex associated 4 homolog & \\
\hline 55989 & 0.8 & 6.3 & Nol5 & Nucleolar protein 5 & \\
\hline 67134 & 0.9 & 7.8 & Nol5a & Nucleolar protein $5 \mathrm{~A}$ & \\
\hline \multicolumn{6}{|c|}{ Small nuclear ribonucleoprotein complex } \\
\hline 68981 & 1.1 & 8.7 & Snrpal & Small nuclear ribonucleoprotein polypeptide $A^{\prime}$ & \\
\hline 20638 & 0.9 & 8.3 & Snrpb & Small nuclear ribonucleoprotein $B$ & \\
\hline 20641 & 1.1 & 7.1 & Snrpd I & Small nuclear ribonucleoprotein DI & \\
\hline 67332 & 1.1 & 7.4 & Snrpd3 & Small nuclear ribonucleoprotein D3 & \\
\hline 69878 & 1.1 & 6.9 & Snrpf & Small nuclear ribonucleoprotein polypeptide $\mathrm{F}$ & \\
\hline 666609 & 1.0 & 7.6 & Snrpg & small nuclear ribonucleoprotein polypeptide $\mathrm{G}$ & \\
\hline \multicolumn{6}{|l|}{ Splicing factor } \\
\hline 110809 & 1.1 & 5.5 & Sfrs I & Splicing factor, arginine/serine-rich I (ASF/SF2) & \\
\hline 20382 & 1.1 & 5.1 & Sfrs2 & Splicing factor, arginine/serine-rich 2 (SC-35) & \\
\hline 20383 & 1.1 & 5.0 & Sfrs3 & Splicing factor, arginine/serine-rich 3 (SRp20) & \\
\hline 81898 & 1.2 & 5.2 & Sf3bl & Splicing factor $3 \mathrm{~b}$, subunit I & 15 \\
\hline 66125 & 1.2 & 8.0 & Sf3b5 & Splicing factor $3 b$, subunit 5 & 15 \\
\hline 225027 & 1.2 & 4.1 & Sfrs7 & Splicing factor, arginine/serine-rich 7 & \\
\hline \multicolumn{6}{|c|}{ RNA binding and pre-mRNA processing factors } \\
\hline 28000 & 1.1 & 4.7 & Prpfl9 & PRPI9/PSO4 pre-mRNA processing factor 19 homolog & \\
\hline 68988 & 1.1 & 5.0 & Prpf3। & PRP3I pre-mRNA processing factor 31 homolog (yeast) & \\
\hline 56194 & 1.1 & 5.8 & Prpf40a & PRP40 pre-mRNA processing factor 40 homolog A (yeast) & \\
\hline 56275 & 0.9 & 5.5 & Rbm 14 & RNA binding motif protein 14 & \\
\hline 67071 & 1.0 & 16.2 & Rps6ka6 (Rsk4) & Ribosomal protein S6 kinase polypeptide 6 & \\
\hline \multicolumn{6}{|c|}{ Spliceosome complex } \\
\hline 81898 & 1.2 & 5.2 & Sf3bl & Splicing factor $3 \mathrm{~b}$, subunit I & 15 \\
\hline 66125 & 1.2 & 8.0 & Sf3b5 & Splicing factor $3 b$, subunit 5 & 15 \\
\hline 20382 & 1.1 & 4.9 & Sfrs2 & Splicing factor, arginine/serine-rich 2 (SC-35) & \\
\hline 68981 & 1.1 & 8.7 & Snrpal & Small nuclear ribonucleoprotein polypeptide $\mathrm{A}^{\prime}$ & \\
\hline 20638 & 0.9 & 8.3 & Snrpb & Small nuclear ribonucleoprotein $B$ & \\
\hline 20641 & 1.1 & 7.1 & Snrpd I & Small nuclear ribonucleoprotein DI & \\
\hline 69878 & 1.1 & 6.9 & Snrpf & Small nuclear ribonucleoprotein polypeptide $\mathrm{F}$ & \\
\hline 666609 & 1.0 & 7.6 & Snrpg & small nuclear ribonucleoprotein polypeptide G & \\
\hline \multicolumn{6}{|c|}{ Cell proliferation and cell cycle regulation related genes } \\
\hline 12428 & 1.0 & 16.6 & Ccna2 & Cyclin A2 & \\
\hline 268697 & 1.2 & 11.2 & Ccnbl & Cyclin BI & \\
\hline 12429 & 1.1 & 17.9 & Ccnbl-rsl & Cyclin BI, related sequence I & \\
\hline 12442 & 0.9 & 17.8 & Ccnb2 & Cyclin B2 & 15,25 \\
\hline 12448 & 1.3 & 4.9 & Ccne2 & Cyclin E2 & \\
\hline 12449 & 0.9 & 8.9 & Conf & Cyclin F & \\
\hline 17216 & 0.9 & 9.0 & Mcm2 & Minichromosome maintenance deficient 2 & 14 \\
\hline 17215 & 0.9 & 8.6 & Mcm3 & Minichromosome maintenance deficient 3 & \\
\hline 17217 & 1.2 & 8.6 & Mcm4 & Minichromosome maintenance deficient 4 & 10 \\
\hline 17218 & 1.0 & 11.8 & Mcm5 & Minichromosome maintenance deficient 5 & \\
\hline 17219 & 1.1 & 20.1 & Mcm6 & Minichromosome maintenance deficient 6 & \\
\hline 17220 & 0.9 & 11.0 & Mcm7 & Minichromosome maintenance deficient 7 & 14 \\
\hline 70024 & 1.1 & 6.3 & Mcm IO & Minichromosome maintenance deficient 10 & \\
\hline
\end{tabular}


Table I: Upregulated genes in primary pancreatic tumors. Relative fold change in primary pancreatic tumors compared to normal pancreas (PT/NP) and in liver metastatic lesions compared to primary pancreatic tumors (LM/PT). (Continued)

\begin{tabular}{|c|c|c|c|c|c|}
\hline 11799 & 1.0 & 11.1 & Birc5 & Baculoviral IAP repeat-containing 5 & \\
\hline$|22| \mid$ & 1.0 & 4.4 & Birc6 & Baculoviral IAP repeat-containing 6 & \\
\hline 12189 & 1.0 & 5.5 & Brcal & Breast cancer I & \\
\hline 70099 & 0.9 & 17.3 & Smc4lI & Structural maintenance of chromosomes 4 & \\
\hline 19361 & 1.0 & $15 . \mid$ & Rad5I & RAD5I homolog (S. cerevisiae) & \\
\hline \multicolumn{6}{|c|}{ Cell adhesion and migration } \\
\hline 12774 & 1.1 & 6.7 & Ccr5 & Chemokine (C-C motif) receptor 5 & \\
\hline 56492 & 1.4 & 6.6 & Cldn 18 & Claudin 18 & 25 \\
\hline \multicolumn{6}{|c|}{ Cell communication and signal trasduction } \\
\hline 75590 & 0.8 & 30.3 & Dusp9 & Dual specificity phosphatase 9 & \\
\hline 67071 & 1.0 & 16.2 & Rps6ka6 (Rsk4) & Ribosomal protein S6 kinase polypeptide 6 & \\
\hline 12774 & 1.1 & 6.7 & Cor5 & Chemokine (C-C motif) receptor 5 & \\
\hline 56275 & 0.9 & 5.5 & Rbml4 & RNA binding motif protein I4 & \\
\hline 12309 & 0.7 & 109.4 & Sioog & SI00 calcium binding protein $\mathrm{G}$ & 10,25 \\
\hline \multicolumn{6}{|c|}{ Apoptosis regulation related } \\
\hline 11799 & 1.0 & 11.1 & Birc5 & Baculoviral IAP repeat-containing 5 & 16 \\
\hline 17218 & 1.0 & 11.8 & Mcm5 & Minichromosome maintenance deficient 5 , & \\
\hline 17319 & 1.1 & 6.8 & Mif & Macrophage migration inhibitory factor & \\
\hline \multicolumn{6}{|c|}{ Chromosome organization and biogenesis } \\
\hline$|42| \mid$ & 1.1 & 12.7 & Smc2II & Structural maintenance of chromosomes 2 & \\
\hline 70099 & 0.9 & 17.3 & Smc4lı & Structural maintenance of chromosomes 4 & \\
\hline 226026 & 1.0 & 5.4 & Smc5ll & Structural maintenance of chromosomes 5 & \\
\hline 19361 & 1.0 & 15.1 & $\operatorname{Rad} 51$ & RAD5I homolog (S. cerevisiae) & 12 \\
\hline 12189 & 1.0 & 5.5 & Brcal & Breast cancer I & \\
\hline 53605 & 0.9 & 13.5 & Nap III & Nucleosome assembly protein I-like I & 10,11 \\
\hline 17216 & 0.9 & 9.0 & Mcm2 & Minichromosome maintenance deficient 2 mitotin & \\
\hline 17218 & 1.0 & 11.8 & Mcm5 & Minichromosome maintenance deficient 5 & \\
\hline \multicolumn{6}{|c|}{ Transcriptional regulator } \\
\hline 22431 & 0.6 & 2.7 & Wtl & Wilms' tumor suppressor gene & 57 \\
\hline
\end{tabular}

NP = Normal pancreas; PT = Primary pancreatic tumor; LM = liver metastatic lesion; Ref. ${ }^{*}=$ References identifying genes previously shown to have deregulated expression in pancreatic cancer

Table 2: Downregulated genes in primary pancreatic tumors. Relative fold change in primary pancreatic tumors compared to normal pancreas (PT/NP) and in liver metastatic lesions compared to primary pancreatic tumors (LM/PT)

\begin{tabular}{|c|c|c|c|c|c|}
\hline Entrez Gene\# & $\begin{array}{l}\text { Fold change } \\
\text { LM/PT }\end{array}$ & $\begin{array}{l}\text { Fold change } \\
\text { PT/NP }\end{array}$ & Gene Symbol & Gene description & Ref.* \\
\hline \multicolumn{6}{|c|}{ Cell adhesion, motility and migration } \\
\hline 12340 & 0.84 & -11.6 & Capzal & Capping protein (actin filament) muscle Z-line, alpha I & 16 \\
\hline 12829 & 0.98 & -10.8 & Col4a4 & Procollagen, type IV, alpha 4 & \\
\hline 13643 & 1.02 & -7.6 & Efnb3 & Ephrin B3 & \\
\hline 215384 & 1.03 & -8 & Fcgbp & Fc fragment of IgG binding protein & \\
\hline 16855 & 1.00 & -6.4 & Lgals4 & Lectin, galactose binding, soluble 4 & \\
\hline |783| & 1.02 & -40 & Muc2 & Mucin 2 & \\
\hline 219228 & 1.51 & -18.8 & Pcdh 17 & Protocadherin 17 & \\
\hline 68799 & 1.20 & -7.2 & Rgmb & RGM domain family, member $B$ & \\
\hline 16855 & 1.00 & -6.4 & Lgals4 & Lectin, galactose binding, soluble 4 & \\
\hline \multicolumn{6}{|c|}{ Cell communication and signal trasduction } \\
\hline 12154 & 1.09 & -4 & Bmplo & Bone morphogenetic protein 10 & \\
\hline 13643 & 1.02 & -7.6 & Efnb3 & Ephrin B3 & \\
\hline 14463 & 1.01 & -8 & Gata4 & GATA binding protein 4 & \\
\hline 15874 & 0.96 & -40 & lapp & Islet amyloid polypeptide & \\
\hline 16333 & 0.85 & -23.2 & $\operatorname{lns} \mid$ & Insulin I & \\
\hline 14526 & 0.91 & -21.6 & Gcg & Glucagon & \\
\hline 70497 & 0.86 & -8 & Arhgap 17 & Rho GTPase activating protein 17 & \\
\hline 232201 & 0.83 & -7.6 & Arhgap 25 & Rho GTPase activating protein 25 & \\
\hline I 10052 & 1.00 & -8.4 & Dek & DEK oncogene (DNA binding) & 16 \\
\hline 14915 & 0.98 & -13.6 & Guca2a & Guanylate cyclase activator $2 \mathrm{a}$ (guanylin) & \\
\hline 212307 & 0.81 & -7.2 & Mapre2 & Microtubule-associated protein, RP/EB family, member 2 & \\
\hline
\end{tabular}


Table 2: Downregulated genes in primary pancreatic tumors. Relative fold change in primary pancreatic tumors compared to normal pancreas (PT/NP) and in liver metastatic lesions compared to primary pancreatic tumors (LM/PT) (Continued)

\begin{tabular}{|c|c|c|c|c|c|}
\hline 20844 & 1.15 & -13.6 & Stam & Signal transducing adaptor molecule & \\
\hline 66042 & 0.85 & -14.8 & Sostdcl & Sclerostin domain containing I & \\
\hline 68799 & 1.20 & -7.2 & Rgmb & RGM domain family, member B & \\
\hline $807 / 8$ & 0.91 & -6.4 & Rab27b & RAB27b, member RAS oncogene family & \\
\hline 18386 & 0.93 & -6 & Oprdl & Opioid receptor, delta I & \\
\hline 67709 & 0.88 & -13.6 & Reg4 & Regenerating islet-derived family, member 4 & \\
\hline \multicolumn{6}{|c|}{ Cell cycle and cell proliferation } \\
\hline 76499 & 1.02 & -8.8 & Clasp2 & CLIP associating protein 2 & \\
\hline 16333 & 0.85 & -23.2 & Insl & Insulin I & \\
\hline 16334 & 0.98 & -40 & Ins2 & Insulin II & \\
\hline 212307 & 0.81 & -7.2 & Mapre2 & Microtubule-associated protein, RP/EB family, member 2 & \\
\hline 22268 & 0.90 & -6 & Upklb & Uroplakin IB & \\
\hline 14526 & 0.91 & -21.6 & Gcg & Glucagon & \\
\hline 212307 & 0.81 & -7.2 & Mapre2 & Microtubule-associated protein, RP/EB family, member 2 & \\
\hline 57263 & I.II & -28 & Retnlb & Resistin like beta & \\
\hline 12154 & 1.09 & -4 & Bmpl0 & Bone morphogenetic protein 10 & \\
\hline$|783|$ & 1.02 & -40 & Muc2 & Mucin 2 & 19 \\
\hline 17063 & 0.91 & -60 & Mucl 3 & Mucin 13, epithelial transmembrane & \\
\hline \multicolumn{6}{|c|}{ Transporter and binding activity } \\
\hline 11773 & 1.09 & -14.8 & Ap2ml & Adaptor protein complex AP-2, mul & \\
\hline 80718 & 0.91 & -6.4 & Rab27b & RAB27b, member RAS oncogene family & \\
\hline 56185 & 1.00 & -19.2 & $\mathrm{HaO} 3$ & Hydroxyacid oxidase (glycolate oxidase) 3 & \\
\hline I I 0052 & 1.00 & -8.4 & Dek & DEK oncogene (DNA binding) & 16 \\
\hline 12829 & 0.98 & -10.8 & Col4a4 & Procollagen, type IV, alpha 4 & \\
\hline 16467 & 1.13 & -11.6 & Atcay & Ataxia, cerebellar, Cayman type homolog (human) & \\
\hline 13487 & 0.95 & -20 & Slc26a3 & Solute carrier family 26 , member 3 & \\
\hline 216156 & 0.92 & -4 & Wdrl8 & WD repeat domain 18 & \\
\hline 69008 & 1.23 & -6.4 & Cab39l & Calcium binding protein 39-like & \\
\hline$|235|$ & 0.84 & -4 & Car4 & Carbonic anhydrase 4 & \\
\hline 72832 & 0.93 & -14.8 & Crtacl & Cartilage acidic protein I & \\
\hline 75600 & 1.20 & -8 & Calml4 & Calmodulin-like 4 & \\
\hline \multicolumn{6}{|c|}{ Apoptosis } \\
\hline 15874 & 0.96 & -40 & lapp & Islet amyloid polypeptide & \\
\hline$|783|$ & 1.02 & -40 & Muc2 & Mucin 2 & 19 \\
\hline $7 \mid 361$ & 1.15 & -8 & Amid & Apoptosis-inducing factor, mitochondrion-associated 2 & \\
\hline 16334 & 0.98 & -40 & Ins2 & Insulin II & \\
\hline 17063 & 0.91 & -60 & Mucl 3 & Mucin 13, epithelial transmembrane & \\
\hline \multicolumn{6}{|c|}{ Transcription activity } \\
\hline 109275 & 0.94 & -4 & Actr5 & ARP5 actin-related protein 5 homolog (yeast) & \\
\hline 71458 & 0.89 & -6 & Bcor & Bcl6 interacting corepressor & \\
\hline 14463 & 1.01 & & Gata4 & GATA binding protein 4 & \\
\hline \multicolumn{6}{|c|}{ Epigenetic and chromatin modification } \\
\hline 213742 & 1.00 & -8.8 & Xist & Inactive $X$ specific transcripts & \\
\hline 75796 & 0.86 & -4 & Cdyl2 & Chromodomain protein, $\mathrm{Y}$ chromosome-like 2 & \\
\hline \multicolumn{6}{|c|}{ Inflammatory and immune response } \\
\hline 21786 & 0.90 & -10.8 & Tff3 & Trefoil factor 3 , intestinal & \\
\hline 15101 & 0.90 & -7.6 & $\mathrm{H} 60$ & Histocompatibility 60 & \\
\hline 94071 & 1.00 & -4 & Clec2h & C-type lectin domain family 2 , member $\mathrm{h}$ & \\
\hline \multicolumn{6}{|c|}{ Cell differentiation } \\
\hline 12154 & 1.09 & -4 & Bmplo & Bone morphogenetic protein 10 & \\
\hline 14463 & 1.01 & -8 & Gata4 & GATA binding protein 4 & \\
\hline 72324 & 0.86 & -4 & Plxdcl & Plexin domain containing I & \\
\hline 20755 & 1.31 & -16 & Sprr2a & Small proline-rich protein $2 \mathrm{~A}$ & \\
\hline 22268 & 0.90 & -6 & Upklb & Uroplakin IB & \\
\hline 75770 & 0.85 & -8.4 & Brsk2 & BR serine/threonine kinase 2 & \\
\hline \multicolumn{6}{|c|}{ Maintenance of cell polarity and shape } \\
\hline 76499 & 1.02 & -8.8 & Clasp2 & CLIP associating protein 2 & \\
\hline 20755 & 1.31 & -16 & Sprr2a & Small proline-rich protein $2 \mathrm{~A}$ & \\
\hline
\end{tabular}

Ref. $^{*}=$ References identifying genes previously shown to have deregulated expression in pancreatic cancer 
A

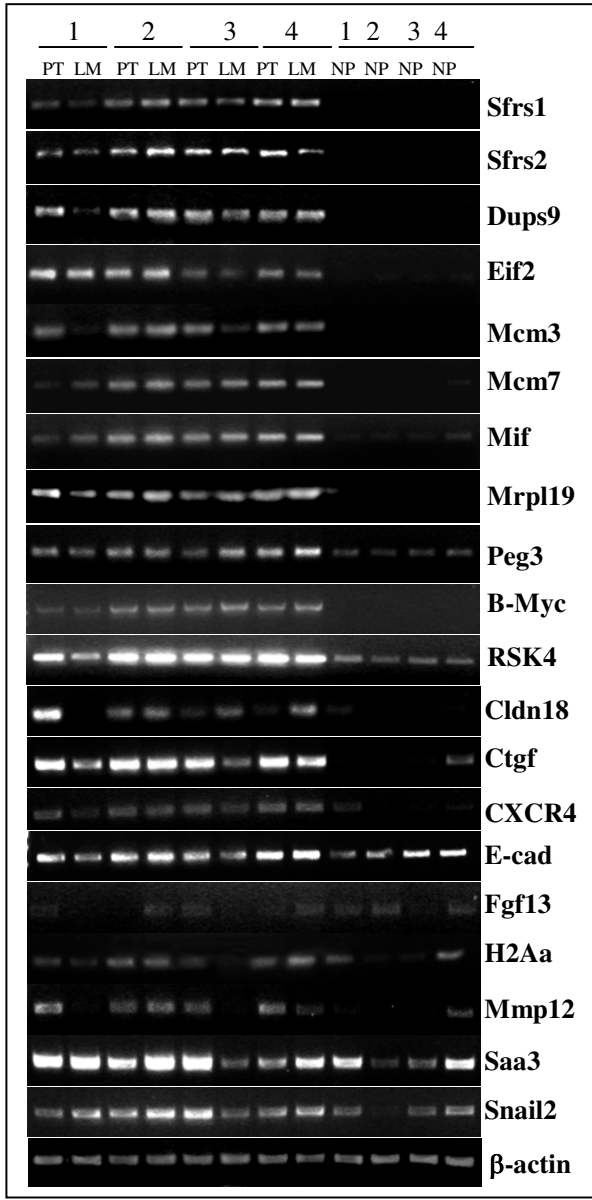

B

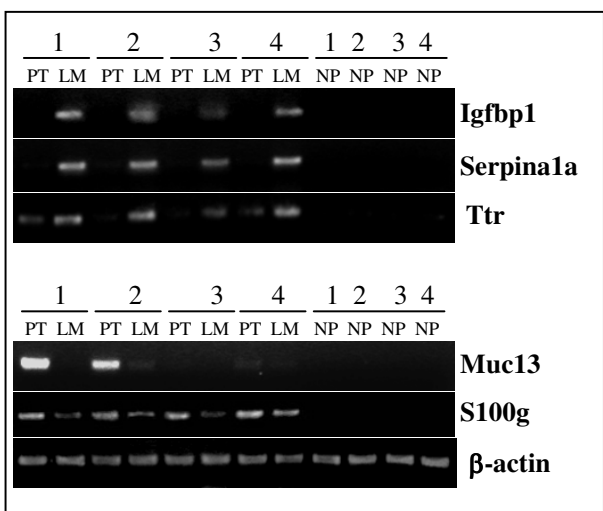

C

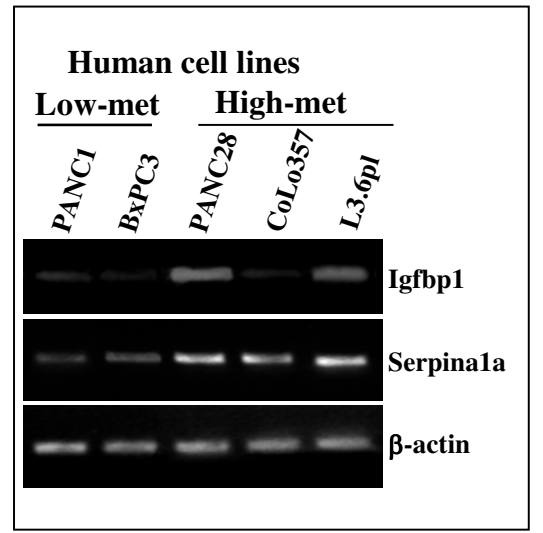

D

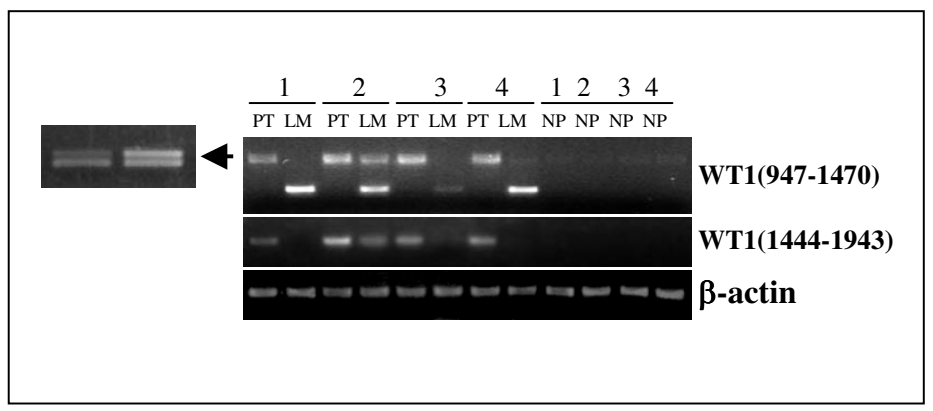

\section{Figure 2}

Selected genes showing up- or down regulation of mRNA expression by semi quantitative RT-PCR. A) All selected genes showed expression pattern similar to microarray data upon confirmation by sqRT-PCR. A representative data from four Ela-c-myc pancreatic tumors, liver metastatic lesions and normal pancreas is presented. B) RT-PCR showing representative differentially expressed genes in liver metastatic lesions compared to primary pancreatic tumors and normal pancreas. C) Two genes, Igfbpl and Serpina la, were verified in human pancreatic cancer cell lines with high (High-met) and low metastatic (Low-met) potentials. Expression patterns of both genes were consistent with the murine microarray and RT-PCR data. D) RT-PCR was performed on RNA from primary pancreatic tumors (PT), liver metastatic lesions (LM) and normal pancreas (NP) with three overlapping primer sets spanning the region from exon I to I0. Primary pancreatic tumors showed presence of both wild type $\mathrm{WtI}$ and $\mathrm{WtI}$ variant without exon 5, while metastatic lesions either lacked expression or had low levels of WtI gene expression (showed a smaller size non-specific PCR product only). 
Table 3: Upregulated genes in liver metastatic lesions. Relative fold change in liver metastatic lesions compared to primary pancreatic tumors (LM/PT) and in primary pancreatic tumors compared to normal pancreas (PT/NP)

\begin{tabular}{|c|c|c|c|c|}
\hline Entrez Gene \# & $\begin{array}{l}\text { Fold change } \\
\text { LM/PT }\end{array}$ & $\begin{array}{l}\text { Fold change } \\
\text { PT/NP }\end{array}$ & Gene Symbol & Gene description \\
\hline \multicolumn{5}{|c|}{ Transporter activity } \\
\hline 27413 & 5.1 & 0.6 & Abcbll & ATP-binding cassette, sub-family B (MDR/TAP), member II \\
\hline 12870 & 11.8 & 0.9 & $C_{p}$ & Ceruloplasmin \\
\hline$|07| 4 \mid$ & 4.2 & 1.1 & Сур2с37 & Cytochrome P450, family 2. subfamily c, polypeptide 37 \\
\hline 76279 & 9.1 & 0.6 & Cyp2d26 & Cytochrome P450, family 2. subfamily d, polypeptide 26 \\
\hline 13107 & 7.8 & 0.3 & Сур $2 \mathrm{f} 2$ & Cytochrome P450, family 2, subfamily f, polypeptide 2 \\
\hline 14263 & 11.3 & 0.4 & Fmo5 & Flavin containing monooxygenase 5 \\
\hline 268756 & 9.0 & 0.5 & Gulo & Gulonolactone (L-) oxidase \\
\hline 20493 & 8.3 & 0.3 & SlclOal & Solute carrier family 10 member I \\
\hline 69354 & 8.3 & 1.0 & Slc38a4 & Solute carrier family 38 , member 4 \\
\hline 28253 & 4.9 & 0.9 & Slcolb2 & Solute carrier organic anion transporter family, member lb2 \\
\hline \multicolumn{5}{|c|}{ Cellular metabolism } \\
\hline 67758 & 10.6 & 0.3 & Aadac & Arylacetamide deacetylase (esterase) \\
\hline 208665 & 11.4 & 0.3 & Akrldl & Aldo-keto reductase family I, member DI \\
\hline 11806 & 43.3 & 0.8 & Apoal & Apolipoprotein A-I \\
\hline 238055 & 12.2 & 0.6 & Apob & Apolipoprotein B \\
\hline 12116 & 33.0 & 0.6 & Bhmt & Betaine-homocysteine methyltransferase \\
\hline $14|2|$ & 9.3 & 0.7 & Fbpl & Fructose bisphosphatase I \\
\hline 22723 I & 33.6 & 0.3 & CpsI & Carbamoyl-phosphate synthetase I \\
\hline 231396 & 14.8 & 1.0 & Ugt2b36 & UDP glucuronosyltransferase 2 family, polypeptide B36 \\
\hline 15233 & 6.9 & 0.4 & $\mathrm{Hgd}$ & Homogentisate I, 2-dioxygenase \\
\hline 15483 & 4.2 & 0.2 & Hsdl Ibl & Hydroxysteroid I I-beta dehydrogenase I \\
\hline 13850 & 7.8 & 0.4 & Ephx2 & Epoxide hydrolase 2, cytoplasmic \\
\hline 13077 & 7.0 & 0.8 & Cypla2 & Cytochrome P450, family I, subfamily a, polypeptide 2 \\
\hline 54150 & 18.2 & 0.5 & Rdh7 & Retinol dehydrogenase 7 \\
\hline 72094 & 7.4 & 1.0 & Ugt2a3 & UDP glucuronosyltransferase 2 family, polypeptide $A 3$ \\
\hline 103149 & 6.3 & 0.6 & Upbl & Ureidopropionase, beta \\
\hline 16922 & 5.4 & 0.4 & Phyh & Phytanoyl-CoA hydroxylase \\
\hline \multicolumn{5}{|c|}{ Calcium binding activity } \\
\hline 19733 & 11.6 & 0.5 & Rgn & Regucalcin \\
\hline 14067 & 6.9 & 0.5 & F5 & Coagulation factor $V$ \\
\hline 16426 & 48.0 & 1.0 & Itih3 & Inter-alpha trypsin inhibitor, heavy chain 3 \\
\hline \multicolumn{5}{|c|}{ Cell organization and biogenesis } \\
\hline 11625 & 40.5 & 0.9 & Ahsg & Alpha-2-HS-glycoprotein \\
\hline 19699 & 5.5 & 0.5 & Reln & Reelin \\
\hline 16008 & 6.0 & 1.0 & lgfbp2 & Insulin-like growth factor binding protein 2 \\
\hline 14080 & 74.7 & 1.0 & Fabpl & Fatty acid binding protein I, liver \\
\hline \multicolumn{5}{|c|}{ Protease Inhibitor activity } \\
\hline 20700 & 24.9 & 4.1 & Serpinala & Serine (or cysteine) peptidase inhibitor, clade A, member la \\
\hline 20702 & 100.1 & 0.4 & Serpinalc & Serine (or cysteine) peptidase inhibitor, clade A, member Ic \\
\hline 59083 & 22.8 & 0.3 & Fetub & Fetuin beta \\
\hline \multicolumn{5}{|c|}{ Inflammatory and Immune response } \\
\hline 12628 & 4.4 & I.I & $\mathrm{Cfh}$ & Complement component factor $h$ \\
\hline 17175 & 4.5 & 1.0 & Masp2 & Mannan-binding lectin serine peptidase 2 \\
\hline 11625 & 40.5 & 0.9 & Ahsg & Alpha-2-HS-glycoprotein \\
\hline 15439 & 14.4 & 7.6 & $\mathrm{Hp}$ & Haptoglobin \\
\hline 18405 & 15.8 & 1.4 & Orm I & Orosomucoid I \\
\hline 12583 & 8.4 & 0.8 & Cdol & Cysteine dioxygenase I, cytosolic \\
\hline 13850 & 7.8 & 0.4 & Ephx2 & Epoxide hydrolase 2, cytoplasmic \\
\hline 11699 & 90.2 & 0.2 & Ambp & Alpha I microglobulin/bikunin \\
\hline \multicolumn{5}{|l|}{ Cell Adhesion } \\
\hline 12558 & 4.7 & 1.0 & $\mathrm{Cdh} 2$ & Cadherin 2 \\
\hline 14067 & 6.9 & 0.5 & F5 & Coagulation factor $V$ \\
\hline 16008 & 6.0 & 1.0 & $\operatorname{lgfbp} 2$ & Insulin-like growth factor binding protein 2 \\
\hline 19699 & 5.5 & 0.5 & Reln & Reelin \\
\hline 17175 & 4.5 & 1.0 & Masp2 & Mannan-binding lectin serine peptidase 2 \\
\hline 14080 & 74.7 & 1.0 & Fabpl & Fatty acid binding protein I, liver \\
\hline
\end{tabular}

Ref.*

25,51 
Table 3: Upregulated genes in liver metastatic lesions. Relative fold change in liver metastatic lesions compared to primary pancreatic tumors (LM/PT) and in primary pancreatic tumors compared to normal pancreas (PT/NP) (Continued)

\begin{tabular}{|c|c|c|c|c|c|}
\hline 14080 & 74.7 & 1.0 & Fabpl & Fatty acid binding protein I, liver & \\
\hline 16008 & 6.0 & 1.0 & Igfbp2 & Insulin-like growth factor binding protein 2 & \\
\hline II625 & 40.5 & 0.9 & Ahsg & Alpha-2-HS-glycoprotein & \\
\hline \multicolumn{6}{|c|}{ Cell motility and migration } \\
\hline 12558 & 4.7 & 1.0 & Cdh2 & Cadherin 2 & \\
\hline 19699 & 5.5 & 0.5 & Reln & Reelin & \\
\hline $1684 \mid$ & 4.8 & 0.6 & Lect2 & Leukocyte cell-derived chemotaxin 2 & \\
\hline 20315 & 4.5 & 0.1 & Cxcll2 & Chemokine (C-X-C motif) ligand I2 & \\
\hline 12738 & 2.8 & 0.3 & Cldn2 & Claudin 2 & \\
\hline \multicolumn{6}{|c|}{ Cell communication and Signal Transduction } \\
\hline 208665 & 11.4 & 0.3 & Akrldl & Aldo-keto reductase family I, member DI & \\
\hline 22139 & 38.8 & 0.1 & Ttr & Transthyretin & \\
\hline 16008 & 6.0 & 1.0 & lgfbp2 & Insulin-like growth factor binding protein 2 & \\
\hline 20526 & 13.1 & 0.3 & Slc2a2 & Solute carrier family 2 , member 2 & \\
\hline 238055 & 12.2 & 0.6 & Apob & Apolipoprotein B & \\
\hline 50765 & 4.4 & 0.7 & Trfr2 & Transferrin receptor 2 & \\
\hline 107146 & 4.7 & 0.7 & Glyat & Glycine- $\mathrm{N}$-acyltransferase & \\
\hline $5|8| 1$ & 5.7 & 0.7 & Clec4f & C-type lectin domain family 4 , member $f$ & \\
\hline 14080 & 74.7 & 1.0 & Fabpl & Fatty acid binding protein I, liver & \\
\hline 56720 & 4.0 & 0.8 & Tdo2 & Tryptophan 2,3-dioxygenase & \\
\hline 11625 & 40.5 & 0.9 & Ahsg & Alpha-2-HS-glycoprotein & \\
\hline 353283 & 4.1 & 42.0 & Eras & ES cell-expressed Ras & \\
\hline 19699 & 5.5 & 0.5 & Reln & Reelin & \\
\hline 16006 & 28.1 & 0.7 & |gfbpl & Insulin-like growth factor binding protein I & $28,30,31$ \\
\hline
\end{tabular}

Ref. $*$ References identifying genes previously shown to have deregulated expression in pancreatic cancer

creas in the wild type littermates, Igf2 expression was dramatically increased (Fig 3A). All three receptors for Igf1 and Igf2 showed only slight increase in their expression, on the other hand all Igf binding proteins (Igfbp1, Igfbp2, Igfbp3, Igf2bp1 etc.) were downregulated compared to normal pancreas. Western blot analysis confirmed increased expression of cleaved, active form of Igf2 (Fig 3B).

\section{Identification of potential metastasis promoting genes in c-myc induced pancreatic tumors}

As mentioned above, we identified a small number of genes that were under various functional categories in metastatic tissues, which were either significantly upregulated or downregulated compared to PT. Interestingly, genes that were downregulated in liver metastatic lesions were comparatively much fewer than upregulated genes. Table 3 shows 4-fold higher and Table 4, 4-fold lower expression levels in LM compared to PT. Most of the highly upregulated genes such as Cp, Apoa1, Ttr in liver metastatic lesions are known biomarkers for the detection of ovarian or other types of cancer [22-24]. Other highly upregulated genes were related to protease inhibition such as Serpina1a, Serpina1c, Ambp [25-27]and insulin growth factor binding proteins such as Igfbp1 and Ifgbp2 [28-31], which have been shown to be upregulated in human pancreatic cancer as well as in the animal models of either pancreatic cancer or other types of cancer. For the verification of some of these genes, we selected two upregulated and two downregulated genes, that showed striking differences from primary pancreatic tumors. In line with our mocroarray data, all LM samples verified by RT-PCR showed highly consistent results (Figure 2B).

\section{Decreased or lost expression of Wt I mRNA in primary pancreatic tumors}

Wt1 is a transcription factor and has been found to be overexpressed in several types of cancers with poor prognosis. Our microarray data showed two-fold higher expression of the Wt1 gene in PT samples compared to NP samples. RT-PCR with a pair of primers that amplify exons 1 to 7 could detect Wt1 mRNA in PT but not in NP and LM (Fig. 2D). Interestingly, liver metastatic lesions expressed a lower molecular species of mRNA. We purified the higher band from primary tumors and the lower band from liver metastatic lesions and sequenced the PCR products. The results showed that the Wt1 mRNA in PT contained both wild type Wt1 and Wt1 variant without exon $5(-51 \mathrm{nt})$. The slight difference in length could be visualized on agarose gel when the PCR products were separated further (Fig. 2D, amplified zone). On the other hand, sequencing results of the band in liver metastatic lesions showed that it was a product of Uroc1 (urocanase domain containing 1) gene, not Wt1. Comparison of the primer sequences with the mouse Uroc1 cDNA (NM_144940) showed high homology, and therefore a non-specific 
A

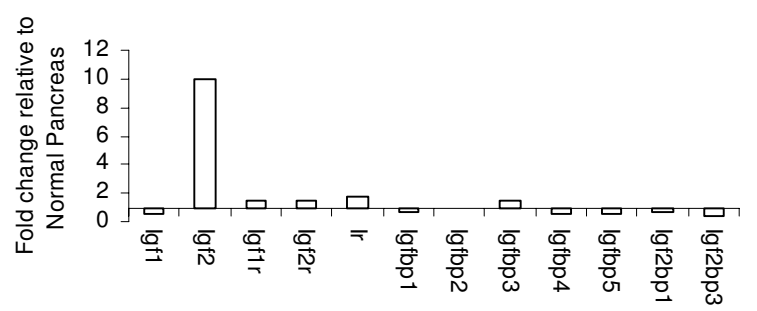

B

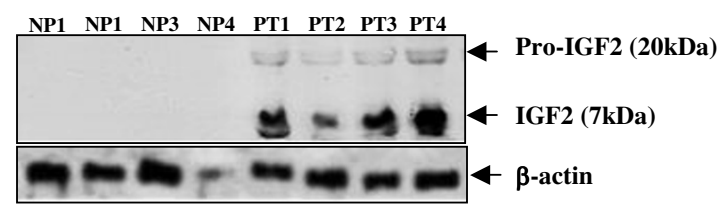

\section{Figure 3}

Expression of IGF family genes and proteins. A)

Microarray data show that expression of Igf2 is about 10 fold higher in pancreatic tumors compared to liver metastatic lesions and normal pancreas from Ela-myc transgenic mice. While other IGF family proteins only showed modest change. B) Western blot analysis of Insulin like growth factors and their receptor proteins. Western blot was performed in cell lysates prepared from primary pancreatic tumors (PT), liver metastatic lesions (LM) from Ela-c-myc transgenic mice and normal pancreas (NP) from wild type littermates. Consistent with microarray data, PT samples showed noticeably higher protein levels compared to NP samples. A representative data from four PT and four NP samples are presented.

band (Uroc1) was amplified with this primer pair. Since human Uroc1 gene is highly expression in hepatoblastoma than in fetal liver [32], it is possible that Uroc1 is preferentially expressed in liver tumors and thus may serve as a marker. PCR with another pair of primers that amplified nt1444-1943 region of the mRNA also showed that LM expressed much lower levels of Wt1. Considering that a tissue is heterogeneous in cell types, it is reasonable to assume that the Wt1 mRNA detected in LM was derived from stromal tissue whereas the cancer cells might have lost Wt1 expression.

\section{Real-time Quantitative Reverse Transcription-PCR Validation}

To confirm the array gene expression data, we performed quantitative reverse transcription-PCR (qRT-PCR) for a selected set $(n=10)$ of genes and the representative data for three genes are shown in Table 4. Although the extent of measured values detected by the two methods varied, an overall pattern concordance between qRT-PCR and
Affymetrix cDNA array experiments was observed (i.e., same trend of induction or suppression was detected by both methods for each target genes). This difference may be due to probe design or the GeneChip system hybridization conditions. For all qRT-PCR, primers specific to $\beta$ actin were used as a control to normalize each experiment. Results are presented in Table 5.

\section{Verification of microarray data in human pancreatic cancer cell lines}

A panel of human pancreatic cancer cell lines that were reportedly to have high or low metastatic potential in immunodeficient mouse models were used to verify the data from Ela-c-myc model of primary and metastatic pancreatic tumors. Cell lines with high metastatic potential include PANC28, CoLo357fg, L3.6pl and low- or nonmetastatic potential include PANC1 and BxPC3. We verified two genes in human cell lines, Igfbp1 and Serpina1a, these genes were highly upregulated in liver metastaic tissues compared to primary pancreatic tumors from transgenic mice. Expression patterns of both genes were consistent with the murine microarray and RT-PCR data (Fig. 2C).

\section{Discussion}

In this study, we report the genome-wide expression profiles of primary pancreatic tumors and liver metastatic lesions from Ela-c-myc transgenic mice, or normal pancreas from wild-type mice. cDNA microarray analysis showed several gene clusters under various functional categories in primary or metastatic pancreatic tumors of Ela$c-m y c$ transgenic mice that differ from normal pancreas of non-transgenic littermates. Notably, increased expression was observed for a large number of genes related to ribosomal biogenesis, maturation and ribosome assembly in primary or metastatic pancreatic tumors. Previous studies by others have also shown enhanced expression of genes related to ribosomal proteins, rRNA maturation and ribosome assembly, in addition to enhanced expression of many translation initiation and elongation factors in cMyc overexpressing cells [33-35]. Thus, our model recapitulates the experimental observations and key features of cMyc overexpressing tumors.

Genes involved in posttranscriptional regulation was a major functional category of upregulated genes in both PT and LM compared to NP samples, we observed changes in expression for splicing factors, RNA binding/pre-mRNA processing factors and spliceosome related genes, indicating that events related to RNA processing may play critical roles in pancreatic tumor development and progression induced by c-Myc. More than $50 \%$ of human genes undergo alternative splicing, and this type of RNA process has recently become an emerging topic in molecular and clinical oncology [36-38]. Our data showed upregulation 
Table 4: Downregulated genes in liver metastatic lesions. Relative fold change in liver metastatic lesions compared to primary pancreatic tumors (LM/PT) and in primary pancreatic tumors compared to normal pancreas (PT/NP)

\begin{tabular}{|c|c|c|c|c|c|}
\hline Entrez Gene \# & LM/PT & PT/NP & Gene Symbol & Gene description & Ref.* \\
\hline \multicolumn{6}{|c|}{ Cell communication and Signal transduction } \\
\hline 22329 & 0.5 & 23.5 & Vcam I & Vascular cell adhesion molecule I & \\
\hline 58194 & 0.4 & 4.0 & Sh3kbpl & SH3-domain kinase binding protein I & \\
\hline 15186 & 0.1 & 15.0 & $\mathrm{Hdc}$ & Histidine decarboxylase & \\
\hline II438 & 0.2 & 4.9 & Chrna4 & $\begin{array}{l}\text { Cholinergic receptor, nicotinic, alpha polypeptide } \\
4\end{array}$ & \\
\hline 12524 & 0.6 & 4.6 & $\mathrm{Cd} 86$ & CD86 antigen & \\
\hline 93761 & 0.2 & 4.2 & Smarcal & $\begin{array}{l}\text { SWI/SNF related, regulator of chromatin, } \\
\text { subfamily a, member I }\end{array}$ & \\
\hline \multicolumn{6}{|c|}{ Cell motility and migration } \\
\hline 12767 & 0.7 & 4.7 & Cxcr4 & Chemokine (C-X-C motif) receptor 4 & 25 \\
\hline$|738|$ & 2.8 & 7.6 & Mmp I 2 & Matrix metallopeptidase 12 & 16 \\
\hline 11438 & 0.2 & 4.9 & Chrna4 & $\begin{array}{l}\text { Cholinergic receptor, nicotinic, alpha polypeptide } \\
4\end{array}$ & \\
\hline \multicolumn{6}{|l|}{ Cell Adhesion } \\
\hline 12505 & 0.6 & 5.3 & $\mathrm{Cd} 44$ & CD44 antigen & II \\
\hline 22329 & 0.5 & 23.5 & Vcam I & Vascular cell adhesion molecule I & \\
\hline \multicolumn{6}{|c|}{ Cell death and apoptosis } \\
\hline 18616 & 0.2 & 11.2 & Peg3 & Paternally expressed 3 & \\
\hline 11801 & 0.6 & 31.1 & $\mathrm{Cd} 5 \mathrm{I}$ & CD5 antigen-like & \\
\hline 58194 & 0.4 & 4.0 & Sh3kbpl & SH3-domain kinase binding protein I & \\
\hline \multicolumn{6}{|c|}{ Inflammatory and Immune response } \\
\hline 20210 & 0.1 & 14.1 & Saa3 & Serum amyloid $\mathrm{A} 3$ & \\
\hline 58194 & 0.4 & 4.0 & Sh3kbpl & SH3-domain kinase binding protein I & \\
\hline 15186 & 0.1 & 15.0 & $\mathrm{Hdc}$ & Histidine decarboxylase & \\
\hline
\end{tabular}

Ref. $^{*}=$ References identifying genes previously shown to have deregulated expression in pancreatic cancer

of several splicing factors from the SR family such as Sfrs 1 , Sfrs2, Sfrs3, Sf3b in both primary and metastatic tumors compared to normal pancreas. SR proteins represent a family of essential splicing factors, which are characterized by extensively phosphorylated serine-arginine rich domains [39]. SR proteins recognize splice sites and, depending on their relative levels, these proteins can influence alternative RNA processing [40].

Other groups of genes that were upregulated are involved in DNA replication, cell proliferation and cell cycle regulation; chromosome organization and biogenesis; and signal transduction. Many genes are related to the maintenance of chromosomal structure and integrity such as minichromosome maintenance $(\mathrm{Mcm}) 2, \mathrm{Mcm} 5, \mathrm{Mcm} 10$, structural maintenance of chromosome (Smc)2l1,
Smc4l1, Smc5l1, Rad51, Brca1 and Centromere component (Cenp-I). The entire $\mathrm{Mcm}$ protein family ( $\mathrm{Mcm} 2-7$ ) is essential in regulating the replication of DNA. Amplification of genes in the Mcm family has been detected in various cancer cells [41]. Their upregulation may deregulate the complete and accurate DNA replication and thus result in failure to maintain the genetic integrity of affected cells. Smc family proteins are integral components of the machinery that modulates chromosome structure for mitosis [42]. Similarly, Rad51, brca1 and Cenp-I play a role in maintenance of genetic integrity $[43,44]$. We also noticed increased expression of some Xlinked genes related to signal transduction such as Rsk4, Dusp9 and S100g, which have not been reported previously in pancreatic tumors.

Table 5: Quantitative RT-PCR. Relative quantity of mRNA expression in PT, LM and NP tissues measured by quantitative real time PCR

\begin{tabular}{lcccccccc}
\hline & \multicolumn{7}{c}{ Relative fold change } \\
\cline { 2 - 9 } Genes & PTI & LTI & PT2 & LT2 & PT3 & LT3 & NPI & NP2 \\
Igfbp I & 14.4 & 70.0 & 2.0 & 20.0 & 10.0 & 90.0 & 2.0 & 2.0 \\
Sepinala & 16.9 & 4.9 & 28.9 & 78.4 & 14.4 & 40.0 & 2.0 & 2.0 \\
Peg3 & 0.4 & 0.2 & 4.9 & 10.0 & 16.0 & 8.1 & 2.0 & 2.0 \\
$\beta$-actin & 1.0 & 1.0 & 1.0 & 1.0 & 1.0 & 1.0 & 1.0 & 1.0 \\
\hline
\end{tabular}


Intriguingly, we observed highly upregulated expression of Igfbp1 and Serpina1 in liver metastatic tissues compared to primary pancreatic tumors and normal pancreas. Verification of Igfbp1 and Serpina1 by RT-PCR and quantitative PCR showed strong expression in liver metastatic lesions but there was a lack of expression of these genes in primary pancreatic tumors or normal pancreas. Similarly, both these genes also showed higher expression in highly metastatic human pancreatic cell lines (PANC28, CoLo357fg, L3.6pl) and lower expression levels in lessmetastatic cell lines (PANC1 and BxPC3). Several studies have described the inhibitory and potentiating activities of both Serpina1 and Igfbp1 in a variety of cells [45-47]. Igfbp 1 interacts with $\alpha_{5} \beta_{1}$ integrin, influencing cell adhesion and migration. Jones et al. [48] first reported the increased migration of Chinese hamster ovary cells transfected to express human Igfbp1. Increased expression of several Igfbps has also been reported in human pancreatic cancer [28-31]. Serpins are endogenous inhibitors of serine protease activity in vivo $[49,50]$ and a large number of studies support the notion that proteases play an important role in the progression of malignant tumors. Therefore, the expression of proteinase inhibitors is considered to be an anti-malignant event. Serpina1, a major inhibitor of human serine proteases in serum, is produced mainly by the liver, but also by extra-hepatic cells, including neutrophils and certain cancer cells [51,52]. However, clinical studies have shown that high circulating levels of Serpina1 directly correlate with tumor progression $[53,54]$. Immunohistochemical studies revealed that patients with Serpina1-positive lung adenocarcinomas had a worse prognosis than Serpina1-negative ones [55]. More interestingly, both Serpina1 and Igfbp1 have been demonstrated to play a role in human invasive and metastatic pancreatic cancer. Together these studies and our findings suggest that Igfbp1 and Serpina1 may play critical roles in tumor progression in vivo, and are potential candidates for therapeutic interventions.

We also compared our gene expression profiles with published data on human pancreatic cancer tissues or cell lines. Gene expression pattern of many genes such as Serpina1, Igfbp1, Wt1, CD44, MMP12, CXCR4, Muc2, Dek, Capza1, Bcra1, Birc5, S100g, Claudin-18, RAD51, $\mathrm{Mcm} 2, \mathrm{Mcm} 4, \mathrm{Mcm} 7$, Cyclin B2, splicing factor 3b, Nap1l1 etc. (please see Tables 1, 2, 3 and 4for references) was similarly reported in other studies and therefore provide a validation for our model.

\section{Conclusion}

We show differential gene expression profiles under several functional categories in normal pancreas, primary pancreatic tumors and liver metastases. We identified two genes, Igfbp1 and Serpina1, which were overexpressed only in liver metastatic lesions suggesting that these genes are likely to be involved in the establishment of metastases in Ela-myc transgenic animal model. In addition, metastatic lesions appear to have low levels or absence of $\mathrm{Wt} 1$ gene expression while primary tumors express at least two major variants (+ exon 5 or - exon 5) Wt1 transcripts. Igfbp1 and Serpina1 may serve as clinically interesting biomarkers are likely to be useful for prognostic or therapeutic purposes in metastatic pancreatic cancer.

\section{Methods \\ Ela-myc transgenic mice}

We used Ela-myc transgenic mice with a FVB background, this strain was generated by crossbreeding of C57BL/6xSJL background Ela-myc [5] mice (obtained from Dr. Sandgren at the University of Wisconsin) with a FVB strain. The F1 mice were crossed together to generate F2 transgenic mice and some of the F2 mice were crossed to yield F3 mice. The F2 and F3 transgenic mice and their wild type littermates were used in this study.

\section{Human Pancreatic cancer cell lines}

A panel of human pancreatic cell lines, PANC1, PANC-28, CoLo357, L3.6pl and BxPC3, were used to verify the microarray data. All pancreatic cell lines were cultured in RPMI 1640 supplemented with $10 \%$ fetal bovine serum, penicillin and streptomycin. Cells were harvested when they were about $80-90 \%$ confluent for RNA isolation.

\section{cDNA microarray}

Primary pancreatic cancer tissue, its corresponding liver metastatic lesion and normal pancreatic tissues were used to prepare RNA using the RNeasy mini kit (Qiagen) per manufacturer's instructions. Assurance of quality assessment and microarray analysis were carried out by personnel in the Applied Genomics Technology Center (Center for Molecular Medicine and Genetics, Wayne State University). Briefly, biotin-labeled RNA fragments were produced from $1 \mu \mathrm{g}$ of RNA by first synthesizing doublestranded cDNA followed by in vitro transcription and fragmentation reactions. A hybridization cocktail, containing the fragmented cRNA, probe array controls, bovine serum albumin, and herring sperm DNA, was prepared and hybridized at $45^{\circ} \mathrm{C}$ for $16 \mathrm{~h}$ to the High Density Mouse Genome M430-2 containing 45101 probesets (Affymetrix Inc., Santa Clara, CA). The hybridized probe array was washed, and bound biotin-labeled cRNA was detected with streptavidin-phycoerythrin conjugate. Each probe array was scanned twice (Hewlett-Packard GeneArray Scanner), the images were overlaid, and the average intensities of each probe cell were compiled. Microarray was repeated three times for each condition (LM, PT, NP).

\section{cDNA microarray data analysis}

High density microarray image files were interpreted and quality assessed to Affymetrix standards in GCOS 1.1 as 
Table 6: List of primer. Primer sets for qRT-PCR and sqRT-PCR

\begin{tabular}{|c|c|c|}
\hline Gene name & Accession No. & Quantitative or sqRT-PCR primer sequence \\
\hline \multicolumn{3}{|l|}{ CXCR4 } \\
\hline Upstream & D87747 & CATGGAACCGATCAGTGTGA $(325)^{*}$ \\
\hline Downstream & & TTTCCCAAAGTACCAGTCAGC \\
\hline \multicolumn{3}{|l|}{ MMP2 } \\
\hline Upstream & NM_008610 & CTGTGTTCTTCGCAGGGAAT (433) \\
\hline Downstream & & TGTGCAGCGATGAAGATGAT \\
\hline \multicolumn{3}{|l|}{ Snail2 } \\
\hline Upstream & NM_0II4I5 & TTCCTCTGACACTTCATCCAA (474) \\
\hline Downstream & & TTGGAGCAGTTTTTGCACTG \\
\hline \multicolumn{3}{|l|}{ E-tcad } \\
\hline Upstream & NM_009864 & CCTGCCAATCCTGATGAAAT (329) \\
\hline Downstream & & TCAGGGA AGGAGCTGAAAGA \\
\hline \multicolumn{3}{|l|}{ Fgf I 3} \\
\hline Upstream & AF020737 & CATTTTCTGCCCAAACCACT (378) \\
\hline Downstream & & AATGCTTGGCACTCTTTTGC \\
\hline \multicolumn{3}{|r|}{ 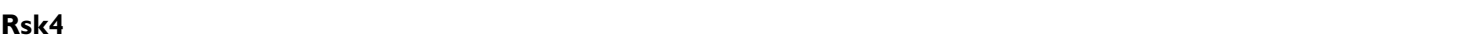 } \\
\hline Upstream & BB4022II & GTGGGTGCCAAAGTTTTGAT (35I) \\
\hline Downstream & & CAAACCACATGGAAATCAGG \\
\hline \multicolumn{3}{|r|}{ 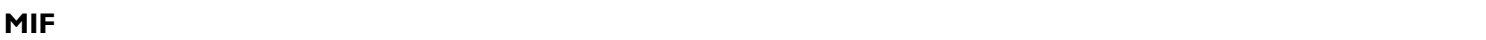 } \\
\hline Upstream & NM_010798.I & ACTACAGTAAGCTGCTGTGTGG (208) \\
\hline Downstream & & ATCGCTACCGGTGGATAAAC \\
\hline \multicolumn{3}{|l|}{ Mcm 7} \\
\hline Upstream & NM_008568.I & ACCGCGAAGTCAGTACACAA (208) \\
\hline Downstream & & GATGGTCTGCTGCTCCATAA \\
\hline \multicolumn{3}{|r|}{  } \\
\hline Upstream & NM_0I3697.I & TGGAAGACACTTGGCATTTC (194) \\
\hline Downstream & & TGCTACTGCTTTGGCAAGAT \\
\hline \multicolumn{3}{|l|}{$\mathrm{H} 2 \mathrm{Aa}$} \\
\hline Upstream & NM_0I0378.2 & ССТTCATCССТTCTGACGAT (197) \\
\hline Downstream & & CAGGCCTTGAATGATGAAGA \\
\hline \multicolumn{3}{|r|}{ ? } \\
\hline Upstream & NM_026490.2 & TGCATCCCATGAAGAAGAGA (183) \\
\hline Downstream & & GACATTTGCTCGTTACAAAAGC \\
\hline \multicolumn{3}{|l|}{ Dusp9 } \\
\hline Upstream & NM_029352.3 & СCTGTGCTTGAGCTCTGATT (I8I) \\
\hline Downstream & & GCTCTCCAAATTGGCTGAAT \\
\hline \multicolumn{3}{|r|}{ 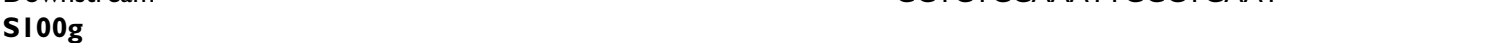 } \\
\hline Upstream & NM_009789.2 & CAGCAAAATGTGTGCTGAGA (197) \\
\hline Downstream & & СTCCATCGCCATTCTTATCC \\
\hline \multicolumn{3}{|l|}{ Serpina la } \\
\hline Upstream & NM_009243 & GCCCTGGCAAATTACATTCT (196) \\
\hline Downstream & & CATTGCCTGCATAATCCATC \\
\hline \multicolumn{3}{|r|}{ 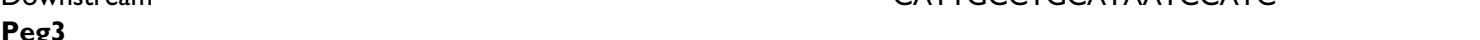 } \\
\hline Upstream & NM_0088I7.2 & ACCATTCAGGCCTCAGTTTC (205) \\
\hline \multicolumn{2}{|l|}{ Downstream } & TTTTCTCAAATTCGCTGACG \\
\hline \multicolumn{3}{|l|}{ Igfbp I } \\
\hline Upstream & NM_00834I & CCTGCCAACGAGAACTCTAT (196) \\
\hline Downstream & & GGGATTTTCTTTCCACTCCA \\
\hline Saa3 & & \\
\hline Upstream & NM_0II3I5.3 & GCGAGCCTACTCTGACATGA (196) \\
\hline Downstream & & ATTGGCAAACTGGTCAGCTC \\
\hline Cldn I 8 & & \\
\hline Upstream & NM_0I98I5.2 & GCTGTACGAGCCCTGATGAT (193) \\
\hline Downstream & & TGTTGGCAAACACAGACACA \\
\hline Sfrs I & & \\
\hline Upstream & NM_I73374.3 & CACTGGTGTCGTGGAGTTTG (190) \\
\hline Downstream & & СTTCTGCTACGGCTTCTGCT \\
\hline Sfrs2 & & \\
\hline Upstream & NM_0I3663.3 & GCTTTGCTTTCGTCGAATTT (I88) \\
\hline Downstream & & AGGACTCCTCCTGCGGTAAT \\
\hline
\end{tabular}


Table 6: List of primer. Primer sets for qRT-PCR and sqRT-PCR (Continued)

\begin{tabular}{|c|c|c|}
\hline \multicolumn{3}{|l|}{ Eif2 } \\
\hline Upstream & NM_026030.2 & GGAGTTGCTGAACCGAGTGT (I80) \\
\hline Downstream & & AGGAGATGTTTGGGTTGACG \\
\hline \multicolumn{3}{|l|}{ Mucl3 } \\
\hline Upstream & NM_010739.I & TGCGTGATGCTACAAAGGAC (195) \\
\hline Downstream & & TGTCCTGGCATTTACTGCTG \\
\hline \multicolumn{3}{|c|}{ Igfbp I (human) } \\
\hline Upstream & NM_000596.2 & AAGGCACAGGAGACATCAGG (195) \\
\hline Downstream & & TATCTGGCAGTTGGGGTCTC \\
\hline \multicolumn{3}{|c|}{ Serpina I (human) } \\
\hline Upstream & NM_00I002235.I & TGCCTGATGAGGGGAAACTA (186) \\
\hline Downstream & & CCCCATTGCTGAAGACCTTA \\
\hline \multicolumn{3}{|c|}{ WTI(362-970) } \\
\hline Upstream & NC_000068 & TCCAGCAGCCGGAGCAACCT (608) \\
\hline Downstream & & AGGGCGTGTGGCCATAGCTG \\
\hline \multicolumn{3}{|c|}{ WTI(947-I470) } \\
\hline Upstream & NC_000068 & CGCCCAGCTATGGCCACACG (523) \\
\hline Downstream & & ATTGCAGCCTGGGTATGCAC \\
\hline \multicolumn{3}{|c|}{ WTI(I444-1943) } \\
\hline Upstream & NC_000068 & TTCATGTGTGCATACCCAGG (499) \\
\hline Downstream & & GTAGATCCACAGTCGTGTCC \\
\hline
\end{tabular}

*PCR product size

described previously [56]. Expression changes were filtered in DChip for fold change ( $>4$ fold) between the experiments. Hierarchical clustering was carried out using Dchip and ontological analysis of gene expression was conducted in both OntoExpress in conjunction with curated pathway analysis using the KEGG Biocarta and GeneGo systems. At least three samples from each condition were used for Affymetrix microarray analysis to select candidate genes. Candidate genes were also confirmed with semi-quantitative, quantitative RT-PCR analysis and/ or western blot at least 3 times.

\section{Semiquantitative RT-PCR}

Total RNA, isolated from the primary or metastatic lesions and normal pancreas of Ela-c-myc transgenic mice, was subjected to first-strand cDNA synthesis using an oligo (dT) primer and Moloney murine leukemia virus (MMLV) reverse transcriptase (Invitrogen). The primer amplified products were separated on ethidium bromide containing $1.2 \%$ agarose gels. Primers for the semiquantitative and quantitative detection of target mRNAs are presented in Table 6.

\section{Real-Time RT-PCR}

cDNA from the primary or metastatic lesions Ela-c-myc transgenic and normal pancreas of wild type mice were subjected to PCR amplification, a maximum of $2 \mu \mathrm{l}$ of each cDNA sample was used per $25-\mu$ l PCR reactions. The real-time measurements were analyzed in triplicate using an automated Real Time Cycler as described previously [56]. The relative quantity in primary tumor versus nor- mal tissue or primary tumor versus metastatic lesion was normalized to $\beta$-actin.

\section{Sequencing of Wilm's tumor suppressor gene (WtI)}

RT-PCR analysis using primers amplified nt947-1470 region of mouse Wt1 mRNA, which covers the first 7 exons, showed that liver metastases (but not primary pancreatic tumors) contained a lower molecular weight mRNA species. To verify the identity of the PCR products of the higher bands in primary tumor and lower band in liver metastatic lesions, we sequenced these bands using forward primer-947 after purifying them from agarose gels using Gel Extraction Kit (QIAEX II) from Qiagen.

\section{Competing interests}

The author(s) declare that they have no competing interests.

\section{Authors' contributions}

AT participated in the design of the study; participated in the experimental design; analysis and interpretation of data; and wrote the manuscript; $\mathrm{AB}$ designed primers; carried out the semi-quantitative and quantitative RT-PCR; JW isolated RNA from tissue samples and did sequencing; DJL participated in the design of the study, monitored and collected primary or metastatic tumor tissues. All authors read and approved the final manuscript.

\section{Acknowledgements}

This work was supported by a grant from Elsa U. Pardee Foundation on pancreatic cancer research. 


\section{References}

I. Yeo TP, Hruban RH, Leach SD, Wilentz RE, Sohn TA, Kern SE, lacobuzio-Donahue CA, Maitra A, Goggins M, Canto MI, et al.: Pancreatic cancer. Curr Probl Cancer 2002, 26(4): I76-275.

2. Schleger C, Verbeke C, Hildenbrand R, Zentgraf H, Bleyl U: c-MYC activation in primary and metastatic ductal adenocarcinoma of the pancreas: incidence, mechanisms, and clinical significance. Mod Pathol 2002, I 5(4):462-469.

3. Mahlamaki EH, Barlund M, Tanner M, Gorunova L, Hoglund M, Karhu $\mathrm{R}$, Kallioniemi A: Frequent amplification of $8 \mathrm{q} 24$, I I q, I 7q, and 20q-specific genes in pancreatic cancer. Genes Chromosomes Cancer 2002, 35(4):353-358.

4. Yamada H, Sakamoto H, Taira M, Nishimura S, Shimosato $Y$, Terada $M$, Sugimura T: Amplifications of both c-Ki-ras with a point mutation and c-myc in a primary pancreatic cancer and its metastatic tumors in lymph nodes. Jpn J Cancer Res 1986, 77(4):370-375.

5. Sandgren EP, Quaife CJ, Paulovich AG, Palmiter RD, Brinster RL: Pancreatic tumor pathogenesis reflects the causative genetic lesion. Proc Natl Acad Sci USA I99I, 88(I):93-97.

6. Liao DJ, Wang Y, Wu J, Adsay NV, Grignon D, Khanani F, Sarkar FH: Characterization of pancreatic lesions from MT-tgfalpha, Ela-myc and MT-tgfalpha/Ela-myc single and double transgenic mice. J Carcinog 2006, 5:19.

7. Liao JD, Adsay NV, Khannani F, Grignon D, Thakur A, Sarkar FH: Histological complexities of pancreatic lesions from transgenic mouse models are consistent with biological and morphological heterogeneity of human pancreatic cancer. Histol Histopathol 2007, 22(6):66I-676.

8. Keleg S, Buchler P, Ludwig R, Buchler MW, Friess $\mathrm{H}$ : Invasion and metastasis in pancreatic cancer. Mol Cancer 2003, 2:14.

9. Kleeff J, Friess H, Berberat PO, Martignoni ME, Z'Graggen K, Buchler MW: Pancreatic cancer - new aspects of molecular biology research. Swiss Surg 2000, 6(5):23I-234.

10. lacobuzio-Donahue CA, Maitra A, Olsen M, Lowe AW, van Heek NT, Rosty C, Walter K, Sato N, Parker A, Ashfaq R, et al.: Exploration of global gene expression patterns in pancreatic adenocarcinoma using cDNA microarrays. Am I Pathol 2003, I62(4): I| III-II62.

II. lacobuzio-Donahue CA, Maitra A, Shen-Ong GL, van Heek T, Ashfaq R, Meyer R, Walter K, Berg K, Hollingsworth MA, Cameron JL, et al.: Discovery of novel tumor markers of pancreatic cancer using global gene expression technology. Am J Pathol 2002, I 60(4): I 239-1249.

12. Maacke H, Jost K, Opitz S, Miska S, Yuan Y, Hasselbach L, Luttges J, Kalthoff $H$, Sturzbecher HW: DNA repair and recombination factor Rad5 I is over-expressed in human pancreatic adenocarcinoma. Oncogene 2000, I9(23):279I-2795.

13. Lynch HT, Deters CA, Snyder CL, Lynch JF, Villeneuve P, Silberstein J, Martin H, Narod SA, Brand RE: BRCAI and pancreatic cancer: pedigree findings and their causal relationships. Cancer Genet Cytogenet 2005, I 58(2): I I9- I 25.

14. Mahlamaki EH, Kauraniemi P, Monni O, Wolf M, Hautaniemi S, Kallioniemi A: High-resolution genomic and expression profiling reveals $\mathbf{1 0 5}$ putative amplification target genes in pancreatic cancer. Neoplasia 2004, 6(5):432-439.

15. Nakamura T, Fidler IJ, Coombes KR: Gene expression profile of metastatic human pancreatic cancer cells depends on the organ microenvironment. Cancer Res 2007, 67(I): I39-I48.

16. Nakamura T, Furukawa $Y$, Nakagawa $H$, Tsunoda T, Ohigashi $H$, Murata K, Ishikawa O, Ohgaki K, Kashimura N, Miyamoto M, et al.: Genome-wide cDNA microarray analysis of gene expression profiles in pancreatic cancers using populations of tumor cells and normal ductal epithelial cells selected for purity by laser microdissection. Oncogene 2004, 23( I 3):2385-2400.

17. Soling A, Sackewitz M, Volkmar M, Schaarschmidt D, Jacob R, Holzhausen HJ, Rainov NG: Minichromosome maintenance protein 3 elicits a cancer-restricted immune response in patients with brain malignancies and is a strong independent predictor of survival in patients with anaplastic astrocytoma. Clin Cancer Res 2005, I I (I):249-258.

18. Sanada Y, Oue N, Mitani Y, Yoshida K, Nakayama H, Yasui W: Downregulation of the claudin- 18 gene, identified through serial analysis of gene expression data analysis, in gastric cancer with an intestinal phenotype. J Pathol 2006, 208(5):633-642.
19. Yonezawa S, Byrd JC, Dahiya R, Ho JJ, Gum JR, Griffiths B, Swallow $D M$, Kim YS: Differential mucin gene expression in human pancreatic and colon cancer cells. Biochem J I99I, 276(Pt 3):599-605.

20. Hollingsworth MA, Swanson BJ: Mucins in cancer: protection and control of the cell surface. Nat Rev Cancer 2004, 4(I):45-60.

2I. Resar LM, Dolde C, Barrett JF, Dang CV: B-myc inhibits neoplastic transformation and transcriptional activation by c-myc. Mol Cell Biol I993, I3(2): I I30- I I36.

22. Griffith OL, Melck A, Jones SJ, Wiseman SM: Meta-analysis and meta-review of thyroid cancer gene expression profiling studies identifies important diagnostic biomarkers. J Clin Oncol 2006, 24(3 I):5043-505 I

23. Moore LE, Fung ET, McGuire M, Rabkin CC, Molinaro A, Wang Z, Zhang F, Wang J, Yip C, Meng XY, et al.: Evaluation of apolipoprotein $A I$ and postranslationally modified forms of transthyretin as biomarkers for ovarian cancer detection in an independent study population. Cancer Epidemiol Biomarkers Prev 2006, I 5(9): I64 I- I646.

24. Weinstein PS, Skinner M, Sipe JD, Lokich JJ, Zamcheck N, Cohen AS: Acute-phase proteins or tumour markers: the role of SAA, SAP, CRP and CEA as indicators of metastasis in a broad spectrum of neoplastic diseases. Scand J Immunol 1984, 19(3): 193-198.

25. Sato N, Fukushima N, Maitra A, lacobuzio-Donahue CA, van Heek NT, Cameron JL, Yeo CJ, Hruban RH, Goggins M: Gene expression profiling identifies genes associated with invasive intraductal papillary mucinous neoplasms of the pancreas. Am J Pathol 2004, I 64(3):903-9|4.

26. Lian Z, De Luca P, Di Cristofano A: Gene expression analysis reveals a signature of estrogen receptor activation upon loss of Pten in a mouse model of endometrial cancer. J Cell Physiol 2006, 208(2):255-266.

27. Liu AY, Zhang H, Sorensen CM, Diamond DL: Analysis of prostate cancer by proteomics using tissue specimens. J Urol 2005, I 73(I):73-78.

28. Mauri P, Scarpa A, Nascimbeni AC, Benazzi L, Parmagnani E, Mafficini A, Della Peruta M, Bassi C, Miyazaki K, Sorio C: Identification of proteins released by pancreatic cancer cells by multidimensional protein identification technology: a strategy for identification of novel cancer markers. Faseb J 2005, I9(9): I I 25-I I 27.

29. Hansel DE, Rahman A, House M, Ashfaq R, Berg K, Yeo CJ, Maitra A: Met proto-oncogene and insulin-like growth factor binding protein 3 overexpression correlates with metastatic ability in well-differentiated pancreatic endocrine neoplasms. Clin Cancer Res 2004, I 0( I 8 Pt I):6I52-6I58.

30. Karna E, Surazynski A, Orlowski K, Laszkiewicz J, Puchalski Z, Nawrat $P$, Palka J: Serum and tissue level of insulin-like growth factorI (IGF-I) and IGF-I binding proteins as an index of pancreatitis and pancreatic cancer. Int J Exp Pathol 2002, 83(5):239-245.

3I. Zumkeller W: IGFs and IGFBPs: surrogate markers for diagnosis and surveillance of tumour growth? Mol Pathol 200I, 54(5):285-288.

32. Yamada S, Ohira M, Horie H, Ando K, Takayasu H, Suzuki Y, Sugano S, Hirata T, Goto T, Matsunaga T, et al.: Expression profiling and differential screening between hepatoblastomas and the corresponding normal livers: identification of high expression of the PLKI oncogene as a poor-prognostic indicator of hepatoblastomas. Oncogene 2004, 23(35):590I-59l I.

33. Johnson JM, Castle J, Garrett-Engele P, Kan Z, Loerch PM, Armour CD, Santos R, Schadt EE, Stoughton R, Shoemaker DD: Genomewide survey of human alternative pre-mRNA splicing with exon junction microarrays. Science 2003, 302(5653):2 |4 |-2 | 44.

34. Pajares MJ, Ezponda T, Catena R, Calvo A, Pio R, Montuenga LM: Alternative splicing: an emerging topic in molecular and clinical oncology. Lancet Oncol 2007, 8(4):349-357.

35. Srebrow A, Kornblihtt AR: The connection between splicing and cancer. J Cell Sci 2006, I I 9(Pt I 3):2635-264I.

36. Venables JP: Aberrant and alternative splicing in cancer. Cancer Res 2004, 64(2I):7647-7654.

37. Brinkman BM: Splice variants as cancer biomarkers. Clin Biochem 2004, 37(7):584-594.

38. Hayes GM, Carrigan PE, Beck AM, Miller LJ: Targeting the RNA splicing machinery as a novel treatment strategy for pancreatic carcinoma. Cancer Res 2006, 66(7):3819-3827. 
39. Zahler AM, Neugebauer KM, Lane WS, Roth MB: Distinct functions of SR proteins in alternative pre-mRNA splicing. Science 1993, 260(5 105):219-222.

40. Stickeler E, Kittrell F, Medina D, Berget SM: Stage-specific changes in SR splicing factors and alternative splicing in mammary tumorigenesis. Oncogene 1999, 18(24):3574-3582.

4I. Bailis JM, Forsburg SL: MCM proteins: DNA damage, mutagenesis and repair. Curr Opin Genet Dev 2004, I 4(I): 17-2I.

42. Hirano T: At the heart of the chromosome: SMC proteins in action. Nat Rev Mol Cell Biol 2006, 7(5):3 I I-322.

43. Amor DJ, Kalitsis $P$, Sumer $H$, Choo $K H$ : Building the centromere: from foundation proteins to 3D organization. Trends Cell Biol 2004, I4(7):359-368.

44. Khanna KK, Jackson SP: DNA double-strand breaks: signaling, repair and the cancer connection. Nat Genet 200I, 27(3):247-254.

45. Kataoka $\mathrm{H}$, Itoh $\mathrm{H}$, Koono $\mathrm{M}$ : Emerging multifunctional aspects of cellular serine proteinase inhibitors in tumor progression and tissue regeneration. Pathol Int 2002, 52(2):89-102.

46. Firth SM, Baxter RC: Cellular actions of the insulin-like growth factor binding proteins. Endocr Rev 2002, 23(6):824-854.

47. Perks CM, Newcomb PV, Norman MR, Holly JM: Effect of insulinlike growth factor binding protein-I on integrin signalling and the induction of apoptosis in human breast cancer cells. $J$ Mol Endocrinol 1999, 22(2): I4I-I50.

48. Jones JI, Doerr ME, Clemmons DR: Cell migration: interactions among integrins, IGFs and IGFBPs. Prog Growth Factor Res 1995, 6(2-4):319-327.

49. Petrache I, Fijalkowska I, Zhen L, Medler TR, Brown E, Cruz P, Choe $\mathrm{KH}$, Taraseviciene-Stewart L, Scerbavicius R, Shapiro L, et al.: A novel antiapoptotic role for alpha I-antitrypsin in the prevention of pulmonary emphysema. Am J Respir Crit Care Med 2006, I73(II): I 222-1228.

50. Zelvyte I, Wallmark A, Piitulainen E, Westin U, Janciauskiene S: Increased plasma levels of serine proteinase inhibitors in lung cancer patients. Anticancer Res 2004, 24(I):24I-247.

5I. Trichopoulos D, Tzonou A, Kalapothaki V, Sparos L, Kremastinou T, Skoutari M: Alpha I-antitrypsin and survival in pancreatic cancer. Int J Cancer 1990, 45(4):685-686.

52. Tzonou A, Sparos L, Kalapothaki V, Zavitsanos X, Rebelakos A, Trichopoulos D: Alpha I-antitrypsin and survival in hepatocellular carcinoma. Br J Cancer 1990, 6I(I):72-73.

53. Higashiyama M, Doi O, Kodama K, Yokouchi H, Tateishi R: An evaluation of the prognostic significance of alpha-I-antitrypsin expression in adenocarcinomas of the lung: an immunohistochemical analysis. Br J Cancer 1992, 65(2):300-302.

54. Sun Z, Yang P: Role of imbalance between neutrophil elastase and alpha $\mathrm{I}$-antitrypsin in cancer development and progression. Lancet Oncol 2004, 5(3): $182-190$.

55. Higashiyama M, Doi O, Kodama K, Yokouchi H, Tateishi R, Matsuura N, Murata A, Tomita N, Monden T, Ogawa M: Immunohistochemical analysis of pancreatic secretory trypsin inhibitor expression in pulmonary adenocarcinoma: its possible participation in scar formation of the tumor tissues. Tumour Biol 1992, 13(56):299-307.

56. Thakur A, Xu H, Wang Y, Bollig A, Biliran H, Liao JD: The role of Xlinked genes in breast cancer. Breast Cancer Res Treat 2005, 93(2): 135-143.

57. Oji Y, Nakamori S, Fujikawa M, Nakatsuka S, Yokota A, Tatsumi N, Abeno S, Ikeba A, Takashima S, Tsujie M, et al.: Overexpression of the Wilms' tumor gene WTI in pancreatic ductal adenocarcinoma. Cancer Sci 2004, 95(7):583-7.

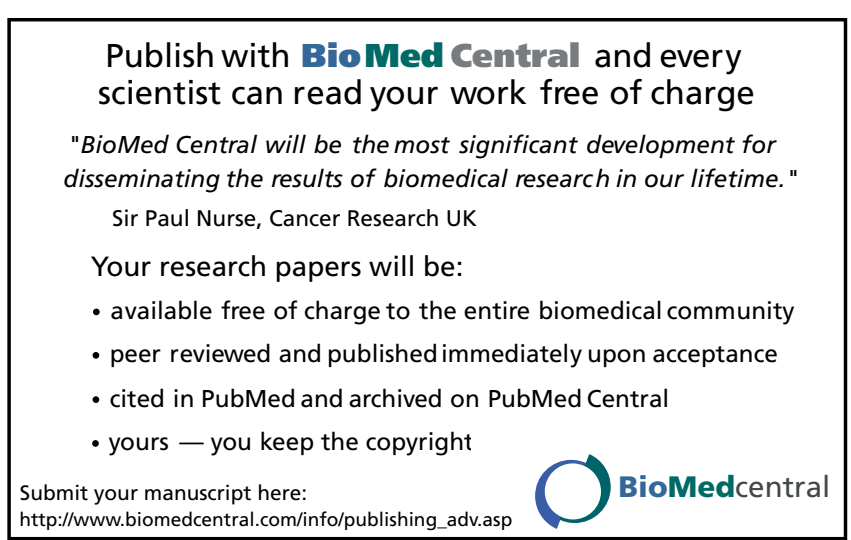

